\title{
Crystalloids and colloids
}

\section{MEA Kemp}

Department of Anaesthesia, Chris Hani Baragwanath Academic Hospital, University of the Witwatersrand, South Africa

Corresponding author, email: meakemp@mweb.co.za

\section{Summary}

Administration of intravenous fluid is like giving drugs, in that they have both beneficial and harmful effects. The composition of intravenous crystalloid and colloid fluids used for resuscitation is described in detail. The use of fluids for intravascular volume replacement is discussed as well as some of the controversies of this in haemorrhagic shock and septic shock.

Keywords: composition of crystalloids, colloids, use of fluids in haemorrhagic and septic shock

\section{Introduction}

The invention' of plastic tubing and catheters in the 1950s made it possible to administer large volumes of fluid intravenously to patients. This use has led to the realisation that intravenous fluids have both beneficial and adverse effects.

\section{Intravenous fluids are drugs}

Malbrain et al. ${ }^{2}$ advocates for considering all intravenous fluids in the same manner as any other drug and for using the concept of 'four Ds' when prescribing fluids:

Drug - consider the indication for the fluid and what effect is being sought.

Duration of therapy - consider when to start and when to stop therapy.

Dosing - consider how much fluid to give.

De-escalation - consider when the fluid therapy is no longer effective or required.

\section{Indications for intravenous fluids}

There are four main indications for intravenous fluid therapy:

1. Resuscitation. A volume expander is an intra-venous fluid that functions to provide volume for the circulatory system.
2. Maintenance or replacement of total body water and electrolytes.

\section{A carrier for medication.}

4. A carrier for parenteral nutrition.

Types of intravenous fluids

\section{Crystalloids ${ }^{3,4}$}

Crystalloid refers to an intravenous solution that contains water, electrolytes and/or non-electrolyte solutes capable of entering all body fluid compartments. Crystalloid solutions can be isotonic, hypertonic, or hypotonic with regard to plasma. Isotonic fluids act to expand the total body water volume without disturbing ion concentrations or causing large fluid shifts. Hypertonic solutions, such as $3 \%$ saline, and hypotonic solutions, such as $5 \%$ dextrose water, are osmotically active and cause fluid shifts. The use of these fluids will not be discussed here.

The strong ion difference (total anions in solution - total cations in solution) determine, in part, the $\mathrm{pH}$ of the fluid. Substances such as acetate, malate, gluconate and lactate are added to crystalloids in order to buffer the solution to a more physiological

Table I: Common isotonic crystalloid solutions used for volume expansion

\begin{tabular}{|c|c|c|c|c|}
\hline Constituent mmol/l & Plasma & $0.9 \%$ saline 'normal saline' & Ringer's lactate & Plasmalyte B \\
\hline $\mathrm{Na}^{+}$ & $136-145$ & 154 & 131 & 130 \\
\hline $\mathrm{K}+$ & $3.5-5$ & & 5 & 4 \\
\hline $\mathrm{Mg}++$ & $0.8-1$ & & & 1.5 (hexahydrate $0.3 \mathrm{~g}$ ) \\
\hline $\mathrm{Ca}++$ & $2.2-2.6$ & & 1.8 & \\
\hline $\mathrm{Cl}-$ & $98-106$ & 154 & 112 & 110 \\
\hline Bicarbonate & & & & 27 \\
\hline Lactate & & & 29 & \\
\hline Strong ion difference & 42 & 27 & 28 & 50 \\
\hline Theoretical osmolality & 291 & 308 & 279 & 294 \\
\hline Actual osmolality & 287 & 286 & 265 & 271 \\
\hline $\mathrm{pH}$ & 7.45 & 5.5 & 6.75 & 7.4 \\
\hline
\end{tabular}




\begin{tabular}{|c|c|c|c|c|c|}
\hline Colloid & Concentration & $\begin{array}{l}\text { Oncotic pressure } \mathrm{mmHg} / \\
\text { osmolarity/mOsm/l }\end{array}$ & $\begin{array}{l}\text { Initial volume } \\
\text { expansion } \%\end{array}$ & Persistence in body & Maximum dose \\
\hline Albumin & $4 \%$ & $20-29$ & 80 & $\begin{array}{l}\mathrm{t} 1 / 220 \text { days intravascular } \\
\text { expansion } 16-24 \text { hours }\end{array}$ & \\
\hline Albumin & $25 \%$ & $100-120$ & $200-400$ & & \\
\hline HES (Voluven) & $6 \%$ in normal saline & $20-29 / 308$ & 80 & $\begin{array}{l}\text { Intravascular expansion } \\
8-12 \text { hours }\end{array}$ & $50 \mathrm{ml} / \mathrm{kg}$ \\
\hline HES (Voluven Lyte) & $\begin{array}{c}6 \% \text { in a balanced salt } \\
\text { solution }\end{array}$ & $\begin{array}{c}20-29 \\
286.5 \mathrm{mOsm} / \mathrm{l}\end{array}$ & 80 & $8-12$ hours & $50 \mathrm{ml} / \mathrm{kg}$ \\
\hline $\begin{array}{l}\text { Gelatin (gelofusine, } \\
\text { haemacel) }\end{array}$ & $\begin{array}{l}3 \% \text { in saline } \mathrm{Na} 154, \\
\qquad \mathrm{Cl} 120\end{array}$ & $\begin{array}{c}26-29 \\
274 \mathrm{mOm} / \mathrm{l}\end{array}$ & 70 & $\begin{array}{l}\text { Intravascular expansion: } \\
2-7 \text { hours }\end{array}$ & \\
\hline Dextran 70 & $6 \%$ & $168-191$ & 200 & 6 days & $1.5 \mathrm{~g}$ \\
\hline
\end{tabular}

$\mathrm{pH}$. These are metabolised to bicarbonate in vivo. Bicarbonate (HCO3-) is incompatible with solutions containing calcium.

The two key differences between normal saline and the other crystalloids are the presence of additional anions in Ringer's and Plasmalyte, and the relative excess of chloride ions in normal saline. Hyperchloraemia from administration of normal saline can cause acidosis. This is usually self-limiting, although there are associated adverse outcomes, including excessive expansion of the extra-cellular fluid, platelet activation, decreased thrombin generation and renal dysfunction.

\section{Colloids $s^{5}$}

In the context of intravenous fluids, a colloid refers to a high molecular weight substance present in a crystalloid solution that initially remains largely within the intravascular space, thereby generating an oncotic pressure. Colloids are either natural, for example, human albumin, or artificial, being either gelatin derivatives, hydroxyethyl starch (HES) or dextran (Table II).

The molecular weight (MW) of a colloid determines the viscosity of the solution. The total weight of the colloid divided by the number of molecules present in solution is called the number average molecular weight $(\mathrm{MN})$ and determines the oncotic pressure. Albumin is monodisperse (albumin molecules are all the same, so MW = MN), but all artificial colloids are polydisperse, with a range of molecule sizes

Albumin and gelatins have a physiological $\mathrm{pH}$, and HES is acidic. The oncoticity (number of molecules in solution) influences the degree of volume expansion - the higher the oncotic pressure, the greater the initial volume expansion. Plasma half life depends on the molecular weight, the elimination route and the organs involved in elimination. This varies with disease states, anaesthesia and surgery. Oncotic pressure is less effective when capillary permeability is increased.

\section{Albumin}

Albumin contributes to about $80 \%$ of the normal oncotic pressure exerted by plasma. It is a single polypeptide chain with 585 amino acids.) Albumin is a natural colloid with few side effects. It is negatively charged, contributing to the formation of a normal ion gap. The high cost of albumin is its main disadvantage.

\section{Hydroxyethyl starches}

These are derivatives of amylopectin, a starch resembling glycogen, derived from maize. Hydroxyethyl groups are added to stabilise the molecule. The $6 \%$ solution is iso-oncotic with plasma and is polydisperse, with molecules ranging in size from $70 \mathrm{kDa}$ to $450 \mathrm{kDa}$. The smaller molecules are rapidly excreted. The continuous excretion reduces the osmotic pressure, a process partially compensated for by degradation of larger particles.

The earlier HES fluids were associated with coagulation dysfunction and pruritis, but the tetrastarches used these days have no effect on bleeding times. Renal impairment in critically ill patients is associated with osmotic nephrosis like lesions in the proximal and distal tubules.

\section{Gelatins}

Gelatins are large polypeptides obtained by hydrolysis of collagen, with either succinylated (gelofusine) or urea cross-linked (haemacel) polypeptides and an average MW of $35000 \mathrm{kDa}$. The carrier is a balanced salt solution. Gelofusine is compatible with blood but haemacel contains calcium.

Gelatins are rapidly excreted by the kidneys, and their duration of action is shorter than that of albumin. There is no evidence of renal dysfunction associated with gelatins. They are the cheapest colloid available, with a shelf life of three years, and there is no upper transfusion limit.

The main disadvantage of gelatins is the occurrence of anaphylactoid reactions, although the exact incidence of this is unclear. The effect on coagulation is also not clear, but they possibly activate coagulation. They do cause increases in plasma renin and aldosterone levels.

\section{Dextrans}

Dextrans are polydisperse, highly branched polysaccharide molecules. They are not used for volume expansion because of a high incidence of anaphylactic reactions and negative effects on coagulation. They are used to improve micro-circulation flow 
in micro-surgical implantations, where the decrease in blood viscosity and inhibition of erythrocyte aggregation are useful.

\section{Use of intravenous fluid for intravascular volume replacement ${ }^{6}$}

The loss of intravascular volume, and not loss of the oxygen carrying capacity of the blood, is the central mechanism of death in haemorrhagic shock.

\section{Fluid replacement in haemorrhagic shock ${ }^{7}$}

Replacement of intravascular volume with albumin and dried plasma has been used since the First World War, when it was also observed that survivors of shock exhibited fluid and salt retention after the initial resuscitation phase. Shires and colleagues in the 1960 s popularised the notion that shock was associated with the loss of large amounts of intravascular and extra-cellular fluids. Resuscitation with large volumes of crystalloid solutions was usual in the Vietnam War - with a corresponding increase in the incidence of 'Da Nung' lung, or acute respiratory distress syndrome (ARDS).

In the 1980s, Shoemaker reported an association between increased cardiac output, oxygen delivery and survival in critically injured patients, and this resulted in large volumes of crystalloid fluid being given to patients. Not only did this prove to have no survival benefit, but resulted in widespread oedema and hypertension, dilutional coagulopathy, ARDS, with increased mortality.

The ROSE ${ }^{2}$ principle has been advocated for in the rational use of fluids in all types of shock. This requires consideration for the various stages involved in fluid therapy, namely:

- Resuscitation phase

- Optimisation phase

- Stabilisation phase

- Evacuation phase

As a result of the wars in Afghanistan and Iraq, a major paradigm shift in the management of haemorrhagic shock has occurred with the development of damage control resuscitation (DCR).

\section{Damage control resuscitation}

The resuscitation of the severely injured and bleeding patient depends just as much on normalising deranged physiology as it does on rapid surgical control of bleeding, and optimal fluid management is key to resuscitation.

Traditionally, severe haemorrhagic shock was treated with infusion of crystalloids, followed sequentially by transfusion of packed red blood cells (PRBC), plasma and platelets. The DCR protocol relies on the early recognition of patients who are going to require massive transfusions (MT) - variously defined but often as requiring ten or more units of PRBC in 24 hours and activation of a massive transfusion protocol (MTP). This has been shown to be associated with a reduced incidence of organ failure and reduced blood product wastage.

\section{DCR principles}

1. Limit the use of crystalloids during resuscitation by early use of transfusion with balanced ratios of PRBC, plasma and platelets.

The PROMTT (prospective, observational, multicentre major trauma transfusion $)^{8}$ study in severe trauma patients revealed that early utilisation of transfusion with PRBC, plasma and platelets in ratios of $1: 1$ or 1:2, with 1 unit of platelets given for every 6-8 units of blood was associated with decreased mortality as compared to other fluid administration regimes. It also revealed that increased crystalloid use was associated with an increase in moderate and severe hypoxia. Although the underlying mechanism of the benefit of the blood, plasma and platelet transfusion regime remains unclear, one hypothesis suggests that the liberal use of crystalloids and artificial colloids increase hydrostatic pressure without repairing endothelial glycocalyx damage, resulting in increased capillary permeability. The infusion of plasma can be complicated by transfusion related acute lung injury (TRALI), characterised by inflammatory mediated pulmonary oedema occurring within hours of transfusing blood products.

2. Permissive hypotension until control of haemorrhage is achieved.

Animal models of haemorrhagic shock suggest that a mean arterial pressure of greater than $60 \mathrm{mmHg}$ is associated with 'popping' of blood clots and rebleeding. A study in humans showed no difference in survival in patients with a systolic blood pressure of $70 \mathrm{mmHg}$ versus those with a systolic blood pressure of $100 \mathrm{mmHg}$.

The exact levels of permissible hypotension are uncertain. A reasonable approach appears to be that in the presence of penetrating trauma, systolic blood pressures of $60-70 \mathrm{mmHg}$ are acceptable. In the case of blunt trauma, systolic pressures of $80-90 \mathrm{mmHg}$ are acceptable and in the presence of traumatic brain injury (TBI), systolic blood pressures of $100-110 \mathrm{mmHg}$ should be maintained.

3. Goal-directed correction of coagulopathy with the use of thromboelastography (TEG) or rotational thromboelastography (ROTEM) and administration of specific clotting factors.

\section{Hypertonic saline resuscitation ${ }^{9}$}

Several in vitro and in vivo studies show benefits of using hypertonic saline solutions as an initial resuscitation fluid but the Resuscitation Outcomes Consortium (ROC) performed a multicentre, randomised trial which revealed a worse incidence of coagulopathies with hypertonic saline as compared with normal saline, although there was no difference in mortality between the two.

\section{Fluid replacement in septic shock}

The rationale for assuming that the shock associated with severe sepsis is caused by decreased tissue perfusion is based upon the occurrence of systemic hypotension, increased blood lactate 
levels and oliguria. This has resulted in the concept of intravascular volume expansion being extended to the treatment of septic shock, although the evidence that increased blood lactate levels in septic shock are indicative of tissue hypoperfusion is lacking.

Volume expansion therapy is commonly used in septic shock and there is evidence that this does improve morbidity and mortality. ${ }^{10}$ The evidence for what fluid and how much should be used remains weak and conflicted. Fluid is less likely to remain intravascularly in sepsis, and there is always a risk of fluid overload when using fluids to treat any type of shock.

Rivers ${ }^{11}$ suggested that early, goal-directed fluid therapy (EGDFT) showed benefit in critically ill patients. EGDFT depends on using 'fluid responsiveness' to direct fluid therapy. Fluid responsiveness is defined as 'a process that consists of predicting, before fluid administration, whether or not subsequent fluid administration will result in an increase in cardiac output.'The increase in cardiac output is measured by dynamic tests and indices to a defined fluid challenge. In general, if the measure of cardiac output increases by $15 \%$ in response to a pre-set fluid bolus, the patient is fluid responsive, and more fluid should be given. Theoretically this will avoid unnecessary fluid administration and reduced excess fluid retention in critical illness, a condition associated with worse outcomes.

However, three recent large randomised controlled trials have not substantiated that the use of EGDFT is carried out correctly

\begin{tabular}{|c|c|}
\hline Trial & Outcome \\
\hline $\begin{array}{l}\text { VASST }^{12} \\
\text { vasopressin in septic } \\
\text { shock }\end{array}$ & $\begin{array}{l}\text { There was no difference in outcomes if } \\
\text { vasopressin or norepinephrine was used in } \\
\text { septic shock. } \\
\text { There is an inverse relationship } \\
\text { between mortality and fluid administration. }\end{array}$ \\
\hline FENICE $^{13}$ & $\begin{array}{l}\text { Methods used to predict fluid } \\
\text { responsiveness are highly variable; whether } \\
\text { patients were deemed fluid responsive or } \\
\text { not did not guide fluid management and } \\
\text { safety limits for fluids were often ignored. }\end{array}$ \\
\hline $\begin{array}{l}\text { FACTT }^{14} \\
\text { catheters and fluids } \\
\text { management in shock }\end{array}$ & $\begin{array}{l}\text { Conservative fluid therapy significantly } \\
\text { improves lung function in ARDS. }\end{array}$ \\
\hline
\end{tabular}

(Table III). Safety limits are not followed, and patients often do not receive less fluid than with conventional therapy.

Current recommendations of the World Health Organization (WHO) are that $30 \mathrm{ml} / \mathrm{kg}$ of fluid should be given to patients with septic shock in the first three hours. However, in a trial of Ugandan children with severe sepsis due to malaria, ${ }^{15}$ a rapid initial bolus of $20-40 \mathrm{ml} / \mathrm{kg}$ of normal saline was associated with increased 48-hour mortality. In another study of severe sepsis fluid treatment in Uganda, ${ }^{16}$ there was no difference in outcomes if patients received fluids according to the WHO guidelines, or not.

\section{The debate: colloids versus crystalloids}

The controversy surrounding whether crystalloids or colloids should be used for volume expansion remains.

Colloids theoretically have the advantage of remaining intravascularly for longer than crystalloids and thereby allow for limiting the amount of fluid therapy received as compared to a crystalloid resuscitation. While a transfusion lasts, crystalloids and colloids exert a similar volume expansion effect. Simulations ${ }^{17}$ suggest that the intravascular half-life $\left(\begin{array}{ll}T & 1 / 2\end{array}\right)$ of crystalloids is $20-40$ minutes, although this may be extended during anaesthesia. Colloids have an intravascular T $1 / 2$ of 2-3 hours, but the distribution, elimination and excretion of colloid molecules are affected by vascular permeability, hypotension, general anaesthesia and surgery.

The endothelial glycocalyx ${ }^{18,19}$ lines the luminal aspect of the vascular endothelium and influences the permeability of fluids across the endothelial barrier. This is damaged in both septic and haemorrhagic shock and this is associated with poorer outcomes. Infusing a colloid solution into a patient with a degraded endothelial glycocalyx may cause interstitial protein/ colloid accumulation, resulting in tissue oedema like that caused by infusion of crystalloids. Infusing colloids similarly cannot reverse pre-existing tissue oedema.

The use of fresh frozen plasma as a resuscitation fluid may have superiority because of its ability to preserve the glycocalyx rather than its ability to restore coagulation factors. There is no evidence that albumin or crystalloid infusion preserves the glycocalyx.

\begin{tabular}{|c|c|}
\hline Trial & Outcome \\
\hline $\mathrm{SALT}^{20}$ & $\begin{array}{l}\text { Among non-critically ill adults treated with intravenous fluids in the emergency department, there was no difference in } \\
\text { hospital-free days between patients treated with balanced crystalloids or normal saline. }\end{array}$ \\
\hline SPLIT ${ }^{21}$ & $\begin{array}{l}\text { Among patients receiving crystalloid therapy in intensive care, there was no difference in the incidence of acute kidney injury } \\
\text { if a balanced salt solution or normal saline was used. }\end{array}$ \\
\hline $\mathrm{SMART}^{22}$ & $\begin{array}{l}\text { Among critically ill adults, the use of balanced crystalloids for intravenous fluid administration results in a lower composite } \\
\text { death rate from any cause, as well as a lower rate of new renal replacement therapy or persistent renal dysfunction, than the } \\
\text { use of normal saline. }\end{array}$ \\
\hline CRISTAL $^{23}$ & $\begin{array}{l}\text { In critically ill patients with symptoms of hypovolaemic shock, use of colloids or crystalloids did not make any difference in } \\
\text { 28-day mortality, although } 90 \text {-day mortality was lower in the colloid group. Renal replacement therapy was similar in both } \\
\text { groups. }\end{array}$ \\
\hline $\mathrm{CHEST}^{24}$ & $\begin{array}{l}\text { No significant difference in } 90 \text {-day mortality in patients resuscitated with } 6 \% \text { HES or saline, but more patients who were } \\
\text { resuscitated with HES required renal replacement therapy. Reanalysis }{ }^{25} \text { of these results in } 2017 \text { showed some differences in } \\
\text { secondary and tertiary outcomes but confirmed support for the original conclusions of the study. }\end{array}$ \\
\hline
\end{tabular}


III Fersenus

caring for life

A Rational, Pragmatic Algorithm for Perioperative Fluid Administration in Adults

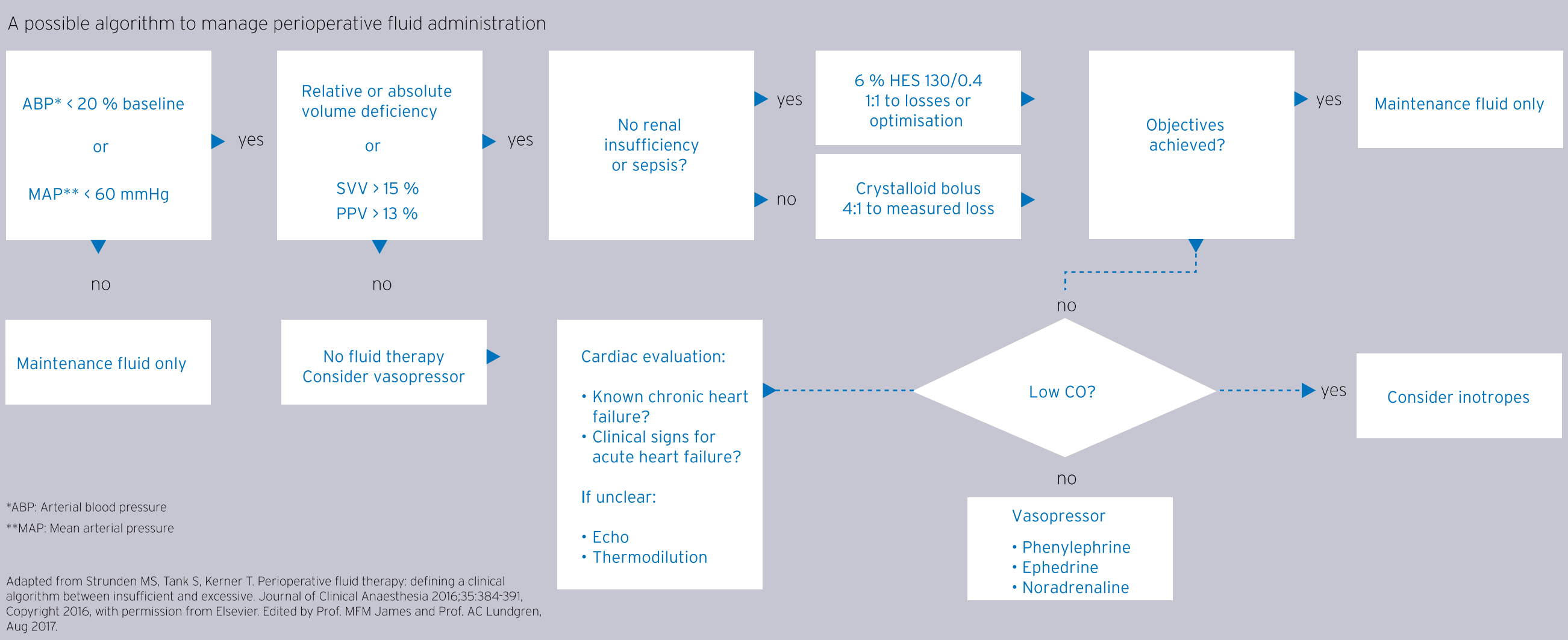

This treatment algorithm, adapted from Strunden et al. 2016 and edited by Prof. MFM James and Prof. AC Lundgren to align it to local clinical practice, is presented by Fresenius Kabi as a service for physicians. Fresenius Kabi does not stipulate exclusive use of its products.

VOLULYTE' VOLUVEN

53 Voluven ${ }^{\oplus}$. Reg. No. 34/8.4/0417. Each $100 \mathrm{ml}$ contains: HES 130/0,4 $6 \mathrm{~g}$. Sodium chloride 0,9 g.

starch you can trus

S3 Volulyte ${ }^{\circledR}$. Reg. No. 41/8.4/0211. Each $100 \mathrm{ml}$ contains: HES 130/0,4 $6 \mathrm{~g}$. Sodium acetate trihydrate 0,463 g. Sodium chloride 0,602 g.

Potassium chloride 0,03 g. Magnesium chloride hexahydrate 0,03 g.

For full prescribing information refer to professional information approved by the South African Health Products Regulatory Authority

Fresenius Kabi South Africa (Pty) Ltd.

Reg. No.: 1998/006230/07

Stand 7, Growthpoint Business Park

162 Tonetti Street

Halway House Extension 7. Midrand

Fax: +27115450060

www.fresenius-kabi.co.za 
HES solutions in vitro do show some protective effects that do not translate into clinical effects.

Colloids are more expensive and at present, there is no evidence of survival benefit in using colloids as opposed to crystalloids as a resuscitation fluid.

In the management of septic shock, it appears that use of HES results in greater renal dysfunction than the use of crystalloids although there was no difference in mortality.

Some trials have attempted to address the problem of which crystalloid to use and whether colloids or crystalloids should be used in the treatment of shock (Table IV).

The Cochrane Systematic Review of 2018, ${ }^{26}$ reviewed 69 randomised control trials (RCT) and 'quasi' RCT comparing the use of colloids and crystalloids in shock and summarised the evidence in the debate as follows:

There is moderately certain evidence that there is little or no difference between using starches, albumin, fresh frozen plasma or crystalloids in mortality at 90 days (RR $0.97 ; 95 \% \mathrm{Cl}$ ).

There is moderately certain evidence that starches probably increase the need for blood transfusion (RR 1.19, 95\% Cl), and uncertain evidence that the use of albumin, fresh frozen plasma or crystalloids increase the need for blood transfusion (RR 0.98).

There is very low certainty evidence that starches cause allergic reactions.

\section{Conclusion}

Intravenous fluid therapy must be considered as a drug with benefits and adverse effects as well as many unanswered questions regarding its use.

\section{Conflict of interest}

The author declares no conflict of interest.

\section{Funding source}

None.

\section{ORCID}

\section{MEA Kemp (D) https://orcid.org/0000-0003-3061-5033}

\section{References}

1. Millam D. The history of intravenous therapy. J Intraven Nurs. 1996;19:5-14.

2. Malbrain ML, Von Regemortel N, Saugel B, et al. Principles of fluid management and stewardship in septic shock: it is time to consider the four D's and the four phases of fluid therapy. Ann Intensive Care. 2018;8:66. https://doi.org/10.1186/ s13613-018-0402-x.

3. Epstein EM, Waseem M. Crystalloid fluids [updated 2019 Nov 23]. In: StatPearls [Internet].Treasure Island (FL): StatPearls Publishing; 2020 Jan.

4. Reddy S, Weinberg L, Young P. Crystalloid fluid therapy. Crit Care. 2016;20:59. https://doi.org:10.1186/51305-016-1217-5.

5. Mitra S, Khandelwal P. Are all colloids the same? How to select the right colloid. Indian J Anaesth. 2009;53:592-607.

6. Pearce JF, Lyons NS. Logistics of parenteral fluids in battlefield resuscitation. Mil Med. 1997;164:653. https://doi.org/10.1093/milmed/164.9.653

7. Chang R, Holcomb JB. Optimal fluid therapy for traumatic haemorrhagic shock Crit Care Clin. 2017;33:15-36. https://doi.org/10.1016/j.ccc.2016.08.007

8. Holcomb JB, Del Junco DJ, Fox EE. The prospective, observational, multi-centre major trauma transfusion (PROMTT) study: comparing effective of a time-varying treatment with competing risks. JAMA Surg. 2013;148:127-36 https://doi.org/10.1001/2013.jamasurg.387

9. Ramesh $\mathrm{GH}$, Uma JC, Farhath S. Fluid resuscitation in trauma: what are the best strategies and fluids? Int J Emergency Med. 2019;12:38

10. Byrne L, Van Haren F. Fluid resuscitation in human sepsis: Time to rewrite history? Ann Intensive Care. 2017;7:4. https://doi.org/10/1186/s13613-016-0231-8.

11. Rivers E, Nguyen B, Havstad S, et al. Early goal-directed therapy in the treatment of severe sepsis and septic shock. N.Engl J Med. 2001;345:1368-77. https://doi org/10.1056/NEJMoa010307.

12. Russell JA, Walley KR, Singer J, et al. Vasopressin versus norepinephrine infusion in patients with septic shock. N Engl J Med. 2008;358:877-87. https://doi. org/10.1056/NEJMoa067373.

13. Cecconi $M$, Hofer $C$, Teboul $J-L$, et al. Fluid challenges in intensive care: the FENICE study: A global inception cohort study. Intensive Care Med. 2015;41:1529-37. https://doi.org/10.1007/s00134-015-3850-x.

14. Grissom CK, Hirshberg El, Dickerson JB, et al. Fluid management with a simplified conservative protocol for acute respiratory distress syndrome. Crit Care Med. 2015;43:2880295. https://doi.org/10.1097/CCM.0000000000000715

15. Maitland K, Kiguli S, Opoka RO, et al. Mortality after fluid bolus in African children with severe infection. N Engl J Med. 2011;364:2482-95. https://doi. org/10.1056/NEJMoa1101549.

16. Amir A, Sautters KJ, Muhindo R, Moore CC. Outcomes of patients with severe infection in Uganda according to adherence to the World Health Organization's Integrated Management of Adolescent and Adult IIIness Fluid Resuscitation Guidelines. J Crit Care. 2017:41:24-28. https://doi.org/10.1016/jcrc.2017.04.042.

17. Hahn RG, Lyons G. The half-life of infusion fluids. An educational review. Eur J Anaesthesiol. 2016;33:475-82. https://doi.org/10.109/EJA.0000000000000436.

18. Mitford EM, Reade MC. Resuscitation fluids choices to preserve the endothelial glycocalyx. Crit Care. 2019;23:77. https://doi.org/10.1186/s13054-019-2369-x.

19. Kim HI, Park S. Sepsis: early recognition and early treatment. Tuberc Respir Dis (Seoul). 2019;82:6-14. https://doi.org/10.4046/trd.2018.0041.

20. Self WH, Semler MW, Wanderer JP, et al. Balanced crystalloids versus saline in non-critically ill adults. N Engl J Med. 2018;378:819-26. https://doi.org/10.1056/ NEJMoa1711586.

21. Young $P$, Bailey $M$, Beasly R. Effect of a buffered crystalloid solution versus saline on acute kidney injury among patients in the intensive care unit. JAMA. 2015;314:1707-10. https://doi.org/10.1001/jama.2015.12334.

22. Semler MW, Self WH, Wanderer JP, et al. Balanced crystalloids versus saline in critically ill adult. N Engl J Med. 2018;378:829-39. https://doi.org/10.1056/ NEJMoa177584.

23. Annane $D$, Shidasp $S$, Jaber $S$. Effects of fluid resuscitation with colloids versus crystalloids on mortality in critically ill patients presenting with hypovolemic shock. JAMA. 2013;310:1809-17. https://doi.org/10.1001/jama.2013.280502.

24. Myburgh JA, Finfer $S$, Belloma $R$, et al. Hydroxyethyl starch or saline for fluid resuscitation in intensive care. $\mathrm{N}$ Engl J Med. 2012;367:1901-11. https://doi. org/10/1056/NEJMoa1209759.

25. Patel A, Pieper K, Myburgh JA, Yang Q, Li Q. Reanalysis of crystalloid vs hydroxyethyl starch in the CHEST trial. N Engl J Med. 2017;377:2980300. https:// doi.org/10.1056/NEJMc1703337

26. Lewis SR, Pritchard MW, Evans DJW, et al. Colloids or crystalloids for fluid replacement in critically ill people. Cochrane Systematic Review. 2018. https:// doi.org/10.1002/14651858.CD000567.pub.7. 